\title{
COMPARAÇÃO ENTRE AS TÉCNICAS ANATÔMICAS DE FORMOLIZAÇÃO, GLICERINAÇÃO E PREENCHIMENTO/CORROSÃO NO SISTEMA RESPIRATÓRIO DE CÃES
}

Daniel Barbosa da Silva ${ }^{1}$, Carla Cristina Braz Louly², Júlio Roquete Cardoso ${ }^{3}$, Marcelo Seixo de Brito e Silva ${ }^{3}$, Alberto Côrrea Mendonça ${ }^{3}$, Mariana Alves Vargas Barbosa4, laciara Luana De Xavier Albernaz ${ }^{5}$, Jonas Gabriel Souto de Andrade ${ }^{5}$.

${ }^{1}$ Professor Adjunto de Anatomia Animal, Instituto Federal Goiano - Campus Urutaí, Go. ${ }^{2}$ Professora Adjunta de Farmacologia Veterinária, Instituto Federal Goiano - Campus Urutaí, GO. ${ }^{3}$ Professor Adjunto de Anatomia Animal, Universidade Federal de Goiás - Goiânia, Go. ${ }^{4}$ Médica Veterinária Autônoma ${ }^{5}$ Acadêmicos do curso de Medicina Veterinária, Instituto Federal Goiano - Campus Urutaí, GO. E-mail: iaciara xavier@hotmail.com

\section{RESUMO}

O objetivo das técnicas de conservação de peças anatômicas é preservar a morfologia, consistência, coloração e flexibilidade das mesmas. Dentre as técnicas utilizadas atualmente estão a formolização, a glicerinação e o preenchimento/corrosão, que foram comparadas no presente estudo. Foram utilizadas quatro peças na avaliação de cada técnica. Para a formolização os pulmões foram lavados, dissecados e fixados em formol 10\%. Para a técnica de glicerinação os órgãos foram fixados em formol 10\%, lavados durante 48 horas e posteriormente secos à sombra. Sequencialmente, os órgãos foram submersos em água oxigenada $10 \mathrm{v}$ e novamente secos à sombra. Então, permaneceram submersos em álcool absoluto durante dois meses, foram retirados, secos naturalmente e submersos em glicerina por 30 dias. Para a técnica de preenchimento/corrosão os pulmões foram lavados, depois submergidos em álcool por 24 horas. A traqueia foi canulada para a etapa de fixação, através da cânula foi introduzida uma corrente de ar contínua contendo mistura de álcool e formol na árvore brônquica. Posteriormente, o acrílico foi inserido, as peças foram colocadas na água por 24 horas e logo foi realizada a corrosão com uso do ácido clorídrico. A técnica de glicerinação mostrou-se mais vantajosa quando comparada à formolização, uma vez que apresenta baixo índice de toxicidade e irritação, facilitando o manejo e estudo além de requerer baixo grau de manutenção. Já para a visualização da árvore brônquica, a técnica de preenchimento/corrosão mostrou-se superior às outras, porém esta técnica demanda maior cuidado durante o seu manuseio e armazenamento.

Palavras-chave: anatomia; conservação; pulmões

\section{COMPARISON OF ANATOMICAL TECHNIQUES FORMOLIZATION, GLYCERINATION AND RESIN E INJECTION FOLLOWED CORROSION IN THE RESPIRATORY SYSTEM OF DOGS}

\begin{abstract}
The objective of the techniques of conservation of anatomical pieces is to preserve the morphology, consistency, color and flexibility of the same. Among the techniques currently used are formaldehyde, glycerin and fill/corrosion, which were compared in the present study. Four pieces were used in the evaluation of each technique. For formalinization, the lungs were washed, dissected and fixed in $10 \%$ formalin. For the glycerination technique, the organs were fixed in $10 \%$ formaldehyde, washed for 48 hours, and then dried in the shade. Sequentially, the organs were submerged in hydrogen peroxide 10 and again dried in the shade. Then, they remained submerged in absolute alcohol for two months, were removed, dried naturally, and submerged in glycerin for 30 days. For the filling/corrosion technique the lungs were washed, then submerged in
\end{abstract}


alcohol for 24 hours. The trachea was cannulated for the fixation step, through the canula a continuous air stream containing alcohol and formalin mixture was introduced into the bronchial tree. Subsequently, the acrylic was inserted, the pieces were placed in the water for 24 hours, and soon the corrosion was carried out with hydrochloric acid. The glycerolation technique proved to be more advantageous when compared to formaldehyde, since it presents a low toxicity and irritation index, which facilitated the management and study, besides requiring a low degree of maintenance. However, for the visualization of the bronchial tree, the filling/corrosion technique proved to be superior to the others, but this technique demands greater care during its handling and storage.

Keywords: anatomy; conservation; lungs

\section{INTRODUÇÃO}

Segundo CURY (2013), a conservação de peças anatômicas é feita há mais de cinco mil anos, devido à necessidade do uso de peças cadavéricas para ensino. Assim, o objetivo da conservação é manter a morfologia semelhante à dos animais vivos, além de preservar consistência, coloração e flexibilidade. Atualmente, existem várias técnicas utilizadas para conservação de tecidos animais, dentre elas estão a formolização, a glicerinação e o preenchimento/corrosão que apresentam uma infinidade de vantagens e desvantagens. A descoberta do formol, ou aldeído fórmico, ocorrida em 1868, foi muito importante, sendo este usado em técnicas anatômicas e microscópicas. Esta substância gasosa utilizada em solução aquosa a 40\% foi utilizada pela primeira vez em 1893 e logo foi aplicada em zoologia. Seu uso foi intenso pelo baixo custo, fácil penetração nas peças e ação rápida como fixadora (RODRIGUES, 2010). Entretanto, tem cheiro irritante, lesa mucosas e pele, além disso, tem potencial cancerígeno e teratogênico (VIEIRA et al., 2013).

A glicerina, descoberta por Karl Schelle em 1779, representou um grande impulso na preparação de peças anatômicas, sendo aplicada por Giacomini e por Laskowski associada ao álcool, ao ácido fênico e ao ácido bórico na conservação de cadáveres dos anfiteatros de anatomia, trata-se de um líquido claro, incolor e viscoso, que apresenta uma série de vantagens, como evitar a desidratação dos tecidos, não possuir cheiro irritante, tornar os tecidos mais leves, moles e flexíveis, facilitando assim o estudo da anatomia (RODRIGUES, 2010).

Preenchimento e corrosão é uma técnica usada tanto para repleção de vasos sanguíneos, como também das vias aéreas, vias biliares e via urinária. Após a repleção, as peças são submetidas à ação corrosiva de ácidos para a obtenção e estudo de moldes dos respectivos sistemas. Existe uma grande quantidade de materiais os quais podemos empregar nesta técnica, como: celulóide, que foi utilizado tanto para obtenção de molde de vasos sanguíneos como também para moldes de brônquios; vinilite; resina de poliéster; metil metacrilato; mercox; tardoplasto; resina justi $n^{\circ} 17$; crysticresin 26 C; perpextensol; araldite CY 223 , que é indicado para visualização e estudo dos capilares de órgãos maiores; complucad resinas e látex (RODRIGUES, 2010). Assim, o presente trabalho teve como objetivo comparar as diferentes técnicas utilizadas na conservação de peças do sistema respiratório de cães, considerando as técnicas de formolização, glicerinação e preenchimento/corrosão.

\section{MATERIAL E MÉTODOS}

Para executar as técnicas, foram utilizadas doze peças anatômicas de sistema respiratório de cães. Os animais cedidos pelo laboratório de anatomia animal da UFG foram dissecados para remoção dos pulmões. Para realizar a formolização quatro peças anatômicas foram lavadas com água e dissecadas, objetivando a visualização de estruturas do sistema respiratório. Após a 
realização da dissecação, as peças foram fixadas em solução aquosa de formol a $10 \%$ durante dois meses. Após esse período, as peças foram mantidas em solução de formol a $10 \%$ para posterior análise comparativa entre as técnicas.

$\mathrm{Na}$ técnica de glicerinação, foram empregadas quatro peças anatômicas de sistema respiratório de cães. Os órgãos foram preservados em formol a 10\%, e constantemente lavados apenas com água por um período de 48 horas, assim houve a total retirada do formol presente nas peças, e elas foram secas à sombra. Posteriormente, as peças foram mantidas submersas em peróxido de hidrogênio a $10 \%$ por 48 horas em um recipiente fechado. Então, os órgãos foram retirados da solução, lavados em água e secos de maneira natural à sombra, posteriormente, as peças ficaram submersas em álcool absoluto (99\%) em um recipiente fechado durante dois meses. Foi realizada então a retirada do álcool e novamente a secagem à sombra. Para a finalização da técnica as peças ficaram submersas em glicerina durante 30 dias. Após esse período, as peças foram retiradas da glicerina e deixadas em um escorredor por um período de 8 horas, para que 0 excesso de glicerina fosse retirado (CURY et al., 2013).

$\mathrm{Na}$ execução da técnica de preenchimento/corrosão foram utilizadas quatro peças do sistema respiratório canino, a resina acrílica foi o material de escolha para o preenchimento dos órgãos. Inicialmente, foi feita a lavagem da árvore brônquica com água para eliminação da secreção existente em seu interior e, em seguida, o pulmão foi escorrido e apertado da periferia em direção ao hilo (RODRIGUES, 2010). Foi colocada uma cânula de vidro grossa produzindo uma corrente de ar contínua para o interior da árvore brônquica. $\mathrm{O}$ ar passou, previamente, por um recipiente contendo mistura de álcool e formol, na proporção de 1:1, o processo prolongou-se por algumas horas até a obtenção da fixação e os pulmões ficaram com uma distensão semelhante aquela presente no animal vivo durante a inspiração. As peças permaneceram em um recipiente fechado contendo álcool etílico a $80^{\circ} \mathrm{GL}$ por vinte e quatro horas antes de serem canuladas. Em seguida, a resina acrílica foi injetada a uma pressão moderada até o enchimento completo da árvore brônquica. As peças foram colocadas em água por vinte e quatro horas e subsequentemente, foi executado o processo de corrosão com ácido clorídrico (RODRIGUES, 2010).

Para todas as técnicas as peças foram avaliadas quanto a presença ou ausência de odor, intensidade do odor (fraco, médio ou intenso), consistência (menor, igual ou mais rígido), flexibilidade (menor, igual ou mais flexível), melhor técnica (formolização, glicerinação e preenchimento e corrosão) e peso (menor, semelhante ou maior) em relação a peça in vivo. Para tal avaliação, foram utilizados 40 alunos do Curso de Medicina Veterinária ,que responderam um questionário, classificando as peças dos diferentes métodos optando pelas alternativas descritas anteriormente.

Em todas as técnicas e etapas foram utilizados os equipamentos de proteção individual (EPI's) necessários a segurança do manipulador.

\section{RESULTADOS E DISCUSSÃO}

Os resultados apresentados com base no questionário aplicado mostraram que as peças formolizadas foram classificadas como sendo as que apresentaram odor intenso, consistência rígida, menor flexibilidade em $100 \%$ das análises. As peças glicerinadas foram descritas com ausência de odor em $60 \%$ das avaliações, enquanto $27,5 \%$ dos avaliadores descreveram odor fraco e $12,5 \%$ odor médio. As peças glicerinadas foram classificadas com menor flexibilidade em $100 \%$ das análises. Nas peças corroídas e preenchidas por látex, 100\% delas foram descritas com ausência de odor, $100 \%$ foram classificadas com consistência rígida e menor flexibilidade. Tanto as peças formolizadas, quanto as glicerinadas, apresentaram maior peso em relação as peças in vivo, contudo, as peças preenchidas/corroídas apresentaram-se mais leves em relação as peças in vivo. 
A técnica escolhida por $100 \%$ dos avaliadores como sendo a melhor foi a de preenchimento/corrosão.

As peças glicerinadas apresentaram melhor preservação em relação as peças formolizadas, sendo observado também uma maior flexibilidade e mínimo odor na glicerinação, o que facilita o estudo, pois frequentemente as peças precisam ser manuseadas, por exemplo, para a evidenciação dos lobos pulmonares. Outra vantagem da glicerinação em relação a formolização foi a diminuição do peso, que se dá devido ao não encharcamento dos pulmões durante a realização desta técnica, facilitando assim, o manejo, principalmente, nos casos em que são utilizadas peças obtidas de animais maiores. Outro ponto de destaque é o que os órgãos submetidos à técnica de glicerinação ficam conservados durante décadas com exigência de manutenção somente a cada três anos. O emprego da glicerina torna-se vantajoso, ainda, por não ser uma substância irritativa para olhos e vias aéreas e não ter a capacidade oncogênica e teratogênica presente no formol.

A formolização é um processo realizado com maior facilidade quando comparado as outras técnicas, uma vez que, nesse processo só há a dissecação e a fixação dos pulmões. Para a conservação em glicerina, as peças passam por: dissecação, fixação, lavagens, secagem e ficam submersas em peróxido de hidrogênio, álcool e glicerina. Já para o preenchimento/corrosão os pulmões passam pelos processos de dissecação, lavagem, canulação, fixação com formol e álcool, repleção com a resina acrílica e corrosão. Em contrapartida, as peças formolizadas exigiram maiores cuidados para a manutenção devido à necessidade de submersão contínua em solução formolizada. Esse processo torna as peças encharcadas, pesadas e com odor irritante para as vias aéreas. Outro transtorno relacionado ao formol é a resistência de alguns fungos e microorganismos a esse conservante, podendo causar a deterioração das peças, demandando assim, maior atenção durante manutenção e armazenagem. Porém, não observamos nenhum crescimento de fungos nas peças obtidas neste estudo, provavelmente, pelo pequeno intervalo de tempo em que as peças foram avaliadas e pelo cuidado destinado a manutenção das mesmas. Outra desvantagem observada foi a dificuldade de obtenção e principalmente manipulação das peças formolizadas, pois o odor irritante aos olhos e vias aéreas causou ao manipulador dores de cabeça, tanto durante a etapa de obtenção das peças, quanto após sua manipulação depois de formolizada, mesmo com a utilização dos EPI's necessários.

A técnica de injeção do sistema respiratório com resina acrílica mostrou-se excelente para evidenciação dos brônquios e suas ramificações, sendo possível até a visualização dos bronquíolos, benefícios que a formolização e glicerinação não apresentaram. Porém, a flexibilidade das peças não foi mantida, visto que, após a mistura do pó e do líquido o material se enrijece e apresenta pouca maleabilidade. É uma técnica relativamente fácil de ser executada, no entanto, exige rapidez durante o processo de injeção da resina, visto que, após a mistura do pó e do líquido o material começa a tornar-se polimerizado em aproximadamente vinte segundos, logo, é uma técnica que requer habilidade por parte de quem a está realizando. A árvore brônquica apresentou-se satisfatoriamente resistente à manipulação, mas as peças precisaram ser manuseadas com prudência para evitar a degradação do material. Assim, como na glicerinação, depois de terminado o processo necessitou-se de pouca manutenção, porém, deve-se atentar à armazenagem para que não haja a fragmentação das peças.

Diante do exposto, a técnica de preenchimento e corrosão é a que mais se destacou para a obtenção de moldes do sistema respiratório, devido principalmente, à possibilidade de melhor visualização dos brônquios e suas ramificações, enquanto que, a glicerinação foi preferível em relação a formolização. 


\section{CONCLUSÕES}

Em virtude do que foi exposto neste trabalho, torna-se possível inferir que o uso do processo de formolização tende a ser substituído por outras técnicas. É importante destacar que a principal vantagem apresentada pela formolização sobre as outras técnicas é o seu menor custo para realização, no entanto, observa-se que a substituição do formol melhora a compreensão da anatomia animal, uma vez que o estudo torna-se mais verdadeiro, já que a glicerinação mantém razoavelmente a flexibilidade do pulmão, enquanto que a técnica de preenchimento/corrosão promove melhor visualização das vias aéreas e circulatórias do pulmão. Cada técnica anatômica comparada no presente trabalho possui inúmeras vantagens e desvantagens, mas diante do que foi aqui apresentado os métodos de glicerinação e preenchimento/corrosão tornam o estudo anatômico do sistema respiratório mais claro e agradável, mostrando grande vantagem em relação a formolização por não apresentarem odor e não serem irritantes. Assim, conclui-se que as técnicas de glicerinação e de preenchimento/corrosão para o estudo do sistema respiratório de cães apresentam-se significativamente vantajosas em relação a formolização.

\section{AGRADECIMENTOS}

Ao Instituto Federal Goiano pela disponibilidade da bolsa de Iniciação Científica - PIBIC.

Ao Departamento de Morfologia da Universidade Federal de Goiás pela contribuição com a realização das etapas e interpretação dos resultados.

\section{REFERÊNCIAS}

CURY, F. S.; CENSONI, J. B.; AMBRÓSIO, C. E. Técnicas anatômicas no ensino da prática de anatomia animal. Pesquisa Veterinária Brasileira, v. 33, n. 5, p.688 - 696, Maio 2013. https://doi.org/10.1590/S0100-736X2013000500022

NASCIMENTO, E. M. do et al. Estudo comparativo entre encéfalos de bovinos submetidos a duas técnicas de conservação: formolização e glicerinação. Revista Científica Eletrônica de Medicina Veterinária, v. 19, Julho 2012.

RODRIGUES, H. Técnicas anatômicas. 4. ed [S.I.]: Gm Gráfica \& Editora, 2010.

VIEIRA, I. I. F. et al. Efeitos da utilização do formoaldeído em laboratórios de Anatomia. Revista de Ciências da Saúde Nova Esperança, v. 11, n. 1, p. 97 - 105, Junho 2013. 